\title{
METODE MASSAGE EFFLEURAGE TERHADAP INTENSITAS NYERI PADA PERSALINAN KALA I
}

\author{
Magfirah', Idwar ${ }^{2}$ \\ 1,2Program Studi Kebidanan Langsa Poltekkes Kemenkes Aceh \\ 1email : magfirah.idris79@gmail.com \\ 2email: idwaredo@gmail.com
}

\begin{abstract}
Background: Pain during childbirth is a physiological condition that is generally experienced by almost all women who give birth. This pain is a subjective experience caused by ischemia of the uterine muscle, traction of the uterine ligament, traction of the ovaries, fallopian tubes, distension of the lower part of the uterus, pelvic floor muscles and perineum. One of the non- pharmacological methods in the form of skin stimulation that can reduce labor pain and cause a relaxing effect is massage effleurage.

Objective: To determine the effect of massage effleurage treatment on the intensity of pain during first stage labor in the Rantau Community Health Center, Aceh Tamiang Regency.

Method: This research is a quasi experiment with a post test to control group design approach only. The sample were mothers who gave birth to the first stage of 4-8 $\mathrm{cm}$ opening. The number of samples was 16 respondents ( 8 for the treatment and 8 for the control group). The sampling technique was done by means of purposive sampling. While the data analysis used was univariate (frequency distribution) and bivariate (Independent T-Test).

Results: Independent sample T-test results, in the treatment group effleurage massage treatment obtained an average value of 4.00 and control group 6.25 obtained $p$ value of $0.031(p \leq 0.05)$. There is a significant difference in the average intensity of stage I labor pain between the treatment group and the control group.

Conclusion: There is an effect of the effleurage massage method on the intensity of the first stage labor pain. Suggestions are expected for further research to compare the two non- pharmacological methods to the intensity of scildbirth pain during the 1st stage.
\end{abstract}

Keywords: Massage Flexure, Pain Intensity, and Labor Period.

\section{ABSTRAK}

Latar Belakang: Nyeri saat persalinan merupakan kondisi fisiologis yang secara umum dialami oleh hampir semua ibu bersalin. Nyeri persalinan merupakan sebuah pengalaman subjektif disebabkan oleh iskemik otot uteri, penarikan traksi ligament uteri, traksi ovarium, tuba fallopi, distensi bagian bawah uteri, otot dasar panggul dan perineum. Salah satu metode non farmakologi dalam bentuk stimulasi kulit yang dapat menurunkan nyeri persalinan, menimbulkan efek relaksasi adalah Massage effleurage.

Tujuan : Untuk mengetahui pengaruh metode massage effleurage terhadap intensitas nyeri persalinan kala I di wilayah kerja Puskesmas Rantau Kabupaten Aceh Tamiang.

Metode: Jenis penelitian quasi experiment, dengan pendekatan post test only control group design. Sampel dalam penelitian ini adalah ibu bersalin kala I pembukaan 4-8 cm. Jumlah sampel sebanyak 16 responden (masingmasing 8 responden untuk kelompok perlakuan dan kontrol). Teknik pengambilan sampel dilakukan dengan cara purposive sampling. Analisa data yang digunakan adalah univariat (distribusi frekuensi) dan bivariat (Uji Independet T-Test).

Hasil: Hasil uji Independen Sampel T-test, pada kelompok perlakuan metode massage effleurage didapatkan nilai rata-rata 4,00 dan kelompok kontrol 6,25 diperoleh nilai $p$ sebesar 0,031 ( $p \leq 0.05$ ). Hal tersebut terdapat perbedaan signifikan rata-rata intensitas nyeri persalinan kala I antara kelompok perlakuan dan kontrol.

Kesimpulan: Terdapat pengaruh metode massage effleurage terhadap intensitas nyeri persalinan kala I . Saran diharapkan penelitian lanjutan membandingkan dua metode non farmakologi terhadap intensitas nyeri persalinan kala I.

Saran diharapkan untuk penelitian lebih lanjut untuk membandingkan dua metode non-farmakologis dengan intensitas nyeri scildbirth selama tahap pertama.

Kata Kunci: Massage effleurage, Intensitas Nyeri, Persalinan

PENDAHULUAN 
Persalinan merupakan tantangan fisiologis dan psikologis bagi wanita. Menjelang persalinan semakin dekat, dapat menyebabkan ketakutan dan kekhawatiran, kegembiraan dan kebahagiaan. Nyeri yang berhubungan dengan persalinan sebagai salah satu bentuk nyeri yang paling intens yang biasa dialami oleh seorang wanita bersalin. Sehingga memerlukan Manajemen mengurangi nyeri yang efektif dan memuaskan serta mengurangi komplikasi dalam persalinan (Sheoran \& Panchal, 2015).

Terapi komplemeter merupakan bagian dari teori atau praktik yang perpaduan medis dan konvesional. dokter diharapkan memberikan terapi farmakologis, sedangkan bidan, perawat dan penolong lainnya diharuskan untuk membantu pasien dengan metode psikologis, dan bahkan lebih sering menggunakan pendekatan alternatif. Landasan terapi komplementer ini merupakan metode alternatif berasal dari tradisi atau filsafat Timur. Bebagai negara mulai menggunakan terapi ini seperti Afrika $80 \%$, Kanada $70 \%$, Prancis $49 \%$, Australia, 46\% Francis AS 42\%,Cina 40\%, Belgia $31 \%$ dan Belanda 18\% (Sheoran \& Panchal, 2015) .

Metode non farmakologi yang dapat digunakan untuk menurunkan nyeri persalinan antara lain homeopathy, massage effleurage, imajinasi, umpan balik biologis, terapi musik, akupresure, massage counterpresure, hipnobirthing, waterbirth, relaksasi dan akupuntur (Fatmawati \& Puspita, Farizka, 2017).

Studi yang dilakukan oleh National Birthday Trust terhadap 1000 wanita menunjukan 90\% wanita merasakan manfaat relaksasi dan pijatan untuk meredakan nyeri. Dari studi tersebut menunjukkan bahwa pijatan dapat memberikan manfaat bagi wanita hamil dan wanita bersalin. Wanita yang mendapatkan pijatan selama persalinan mengalami penurunan kecemasan, pengurangan nyeri dan waktu persalinan lebih pendek secara bermakna (Rosalinna, 2017). Nyeri setiap indivdu dalam persalinan berbeda beda hali ini dipengaruhi oleh beberapa factor tersebut diantaranya lingkungan, dukungan orang terdekat,usia dan pengalaman nyeri masa lalu. (Sunarsih,2017)

Mencegah terjadinya berbagai komplikasi dalam persalinan, maka tenaga kesehatan khususnya bidan mempunyai tanggung jawab dan tantangan dalam memberikan asuhan yang adekuat untuk membantu proses persalinan. Namun hal tersebut bukan merupakan tugas yang mudah bagi seorang bidan karena setiap wanita memiliki dimensi biologi, psikologi, sosial, spiritual, budaya dan pendidikan berbeda yang berdampak terhadap cara mengekspresikan diri dan mempersepsikan rasa nyeri saat persalinan yang merupakan bagian alami dari proses persalinan. Berbagai literatur telah banyak yang membahas berbagai teknik untuk mengurangi nyeri secara nonfarmakologik, tetapi dalam praktiknya tidak semudah apa yang dibayangkan karena belum terdapat tuntunan yang jelas tentang penanganan nyeri selama persalinan (Karunia, Ni Putu, 2017).

Berdasarkan latar belakang tersebut maka peneliti ingin mengetahu apakah ada pengaruh metode massage effleurage terhadap intensitas nyeri persalinan kala I di wilayah kerja Puskesmas Rantau Kabupaten Aceh Tamiang

\section{METODOLOGI PENELITIAN}

Jenis penelitian yang digunakan adalah Quasi experiment design (eksperimen semu) dengan pendekatan Post test only control group design. Penelitian ini dilakukan di wilayah kerja Puskesmas Rantau Kabupaten Aceh Tamiang, pada bulan Mei s/d Juni 2019. Populasi dalam penelitian ini adalah semua ibu bersalin kala I yang ada di wilayah kerja Puskesmas Rantau Kabupaten Aceh Tamiang. Sampel dalam penelitian ini adalah ibu bersalin kala I pembukaan 4-8 cm. Pemilihan sampel sesuai dengan kriteria inklusi yaitu ibu bersalin normal, usia antara 20-40 tahun, tidak mempunyai kelainan jantung, tidak menjalani terapi analgesik selama persalinan, kooperatif dan dapat berkomunikasi dengan baik, bersedia menjadi responden. Adapun kriteria eksklusi yaitu ibu bersalin kala I dengan gawat janin, ketuban pecah dini (KPD), post SC, kala II memanjang, persalinan dengan komplikasi pada kala I dan grande multipara. Jumlah sampel penelitian sebanyak 16 responden (masing-masing 8 responden untuk kelompok perlakuan dan kontrol) Teknik pengambilan sampel yaitu Purposive Sampling. Frekuensi masage effleurage pada setiap responden dilakukan sebanyak 5 kali dengan durasi 5 menit dengan jarak waktu antara masase 20 menit Pengamatan rasa nyeri pada ibu bersalin kala I dilakukan 30 menit setelah masase terakhir. Instrumen untuk mengukur intesitas nyeri menggunakan lembar observasi (Behavioural assessment scale). Analisa data yang digunakan adalah univariat (distribusi frekuesi) dan bivariat (Uji Independet T-Test).

\section{HASIL}

\section{Analisa Univariat}

Berdasarkan hasil penelitian didapatkan karakteristik responden sebagai berikut:

Tabel 1. Karakteristik Responden 


\begin{tabular}{lcc}
\hline Karakteristik & $\begin{array}{c}\text { Frekuensi } \\
(\mathbf{f})\end{array}$ & $\begin{array}{c}\text { Persentase } \\
(\%)\end{array}$ \\
\hline Usia & 3 & \\
$<20$ & 11 & 18,7 \\
$20-35$ & 2 & 68,8 \\
$>35$ & & 12,5 \\
Tingkat & 7 & 43.8 \\
Pendidikan & 5 & 31,2 \\
Dasar & 4 & 25,0 \\
Menengah & & \\
Tinggi & & \\
Paritas & 10 & 62,5 \\
Primipara & 6 & 37,5 \\
Multipara & 16 & 100 \\
\multicolumn{1}{c}{ Total } & & \\
\hline
\end{tabular}

Berdasarkan tabel 1 diketahui mayoritas usia responden yaitu 20-35 tahun sebanyak 11 responden $(68,8 \%)$, dengan tingkat pendidikan Sekolah Dasar 7 responden $(43,8 \%)$ dan Paritas Primipara sebanyak 10 responden $(62,5 \%)$.

\section{Analisa Bivariat}

Tabel 2.

Uji Normalitas

\begin{tabular}{lcc}
\hline \multicolumn{1}{c}{ Kelompok } & Sig & Kemaknaan \\
\hline Massage Effelurage & 0,416 & Berdistribusi Normal \\
Kontrol & 0,825 & Berdistribusi Normal \\
\hline
\end{tabular}

Hasil uji Shapiro-wilk didapatkan nilai sig atau $p$-value diatas $0,05 \quad(p>0,05)$ baik kelompok perlakuan mapun kontrol hal ini merupakan data berdistribusi normal.

Berdasarkan hasil uji homogen di table 3 diperoleh nilai signifikansi (sig) sebesar 0,617. ( $p=$ $\geq 0.05$ ) maka dapat disimpulkan bahwa kedua kelompok tersebut adalah sama atau homogen.

Tabel 3.

Uji Homogen

\begin{tabular}{lcc}
\hline \multicolumn{1}{c}{ Kelompok } & Sig & Kemaknaan \\
\hline $\begin{array}{l}\text { Massage Effelurage } \\
\text { Kontrol }\end{array}$ & 0,617 & Homogen \\
\hline
\end{tabular}

Pada kelompok perlakuan massage effleurage didapatkan nilai rata-rata 4,00 dan kelompok kontrol 6,25 artinya intensitas nyeri persalinan pada kelompok control lebih rendah dari kelompok kontrol. Tampak pada tabel diatas $p$-value intensitas nyeri persalinan pada kelompok massage effleurage dan kontrol adalah 0,031 yang berarti ada penurunan intensitas nyeri persalinan yang signifikan. Untuk nilai signifikansi (sig) pada kelompok kontrol dan masage effleurage didapati sebesar 0,031 ( $p=<0,05$ ) maka terdapat disimpulkan adanya perbedaan intensitas nyeri persalinan yang signifikan antara kelompok perlakuan dan kontrol terhadap intensitas nyeri persalinan kala I.

Tabel 4.

Hasil uji Independen T test Massage Effleurage Terhadap Intensitas Nyeri Pada Persalinan Kala I

\begin{tabular}{lccc}
\hline \multicolumn{1}{c}{ Kelompok } & Mean & SD & Sig \\
\hline Massage Effelurage & 4,00 & 1,51186 & 0,031 \\
Kontrol & 6,25 & 2,18763 & \\
\hline
\end{tabular}

\section{PEMBAHASAN}

Hasil penelitian ini menunjukkan adanya perbedaan intensitas nyeri persalinan yang signifikan antara kelompok perlakuan dan kontrol terhadap intensitas nyeri persalinan kala I, dimana kelompok massage effleurage didapatkan nilai rata-rata 4,00 dan kelompok kontrol 6,25 dengan $p$-value 0,031.

Nyeri persalinan adalah pengalaman yang paling parah pada wanita, oleh karena itu, beberapa metode telah diterapkan untuk menghilangkan nyeri persalinan yang terdiri dari terapi pijat. Terapi pijat selama tahap pertama persalinan menunjukkan secara signifikan menurunkan intensitas nyeri pada wanita (Sadat et al., 2016).

Penurunan nilai nyeri ditemukan secara signifikan lebih besar pada kelompok massage efflurage dibandingkan dengan kelompok kontrol ( $p$ $<0,05)$. Hal ini menunjukkan bahwa massage efflurage lebih baik daripada kelompok kontrol. Pijat ditujukan untuk mempengaruhi sistem motorik, saraf dan kardiovaskular, memicu istirahat dan relaksasi di seluruh tubuh dan pernapasan. Selain itu, pemijatan juga bertujuan untuk mengembalikan aliran vena dan getah bening, menstimulasi reseptor sensorik di kulit dan sub kulit untuk mengurangi rasa nyeri. Begitu juga hormon relaxin berfungsi untuk mengendurkan ligamen di panggul untuk proses persalinan, hormon ini juga melemaskan ligamen penyangga tulang belakang sehingga memberikan relaksasi (Wulan et al., 2017).

Hal ini sesuai dengan teori gate control dalam Wulandari (2012) yang mengatakan bahwa nyeri akan berkurang setelah dilakukan massage effelurage karena sentuhan dan nyeri dirangsang bersama sensasi sentuhan berjalan ke otak dan menutup gerbang dalam otak dan terjadi pembatasan intensitas nyeri di otak (Wulandari \& Dwi, Prasita, 2015). 
Massage effleurage merupakan suatu metode non farmakologi yang merupakan salah satu teknik menghilangkan rasa sakit yang paling efektif. Massage effleurage merupakan manipulasi sistematis jaringan lunak terutama otot, tendon dan kulit. Hal ini juga berguna untuk melemaskan otototot yang tegang dan menimbulkan relaksasi (Rahman, et al, 2017)

\section{SIMPULAN}

Terdapat pengaruh metode massage effleurage terhadap intensitas nyeri persalinan kala I dengan nilai rata-rata kelompok perlakuan 4,00 dan kelompok kontrol 6,25 p-value 0,031.

\section{SARAN}

Diharapkan penelitian lanjutan membandingkan dua metode non farmakologi terhadap intensitas nyeri persalinan kala I. Diharapkan kepada bidan agar dapat menerapkan secara rutin metode terapi non farmakologi dalam membantu persalinan agar dapat berjalan dengan baik salah satunya metode massage effleurage.

\section{DAFTAR PUSTAKA}

Fatmawati, \& Puspita, Farizka, A. (2017). Efektifitas Masase Efflurage Terhadap Pengurangan Sensasi Rasa Nyeri Persalinan Pada Ibu Primipara. Journal of Issues in Midwifery, 1(2), 42-49.

Karunia, Ni Putu, E. (2017). Kombinasi Teknik Relaksasi dan Pijatan Bagi Ibu Bersalin Terhadap Penurunan Intensitas Nyeri, Lama Persalinan dan Apgar Score Bayi Baru Lahir. Kesehatan Prima, I(2), 93-103.

Rahman, S.A., Handayani, A., Maryam, A., Sumarni., Mallongi, A. (2017). Penurunan Nyeri
Persalinan denagan Kompres Hangat dan Massage Effluerage. Jurnal MKMI, Vol. 13 No.2.

Rosalinna. (2017). Pengaruh Massage Effleurage Terhadap Pengurangan Rasa Nyeri Pada Persalinan Kala I Fase Aktif di Wilayah Kerja Puskesmas Kemalang. CARING, 1(272), 5561.

Sadat, H. Z., Forugh, F., Maryam, H., Nosratollah, M. N., Hosein, S., Khoochak, M., ... Sciences, M. (2016). The Impact of Manual Massage on Intensity and Duration of Pain at First Phase of Labor in Primigravid Women. International Journal of Medicine Research, 1(4), 18-20.

Sheoran, P., \& Panchal, R. (2015). A Study to Assess the Effectiveness of Abdominal Effleurage on Labor Pain Intensity and Labour Outcomes Among Nullipara Mothers During 1 st Stage of Labor In Selected Hospitals of District. International Journal of Science and Research (IJSR), 4(1), 1585-1590

Sunarsih, S., Maternity, D., \& Astuti, N. P. R. (2017). Terapi Musik Klasik mengurangi nyeri pada kala I Persalinan di BPS Zubaedah Syah, S. ST Palapa Bandar Lampung 2016. JURNAL DUNIA KESMAS, 6(1).

Wulan, S., Soejoenoes, A., M, S. W., Hidayat, S. T., Widyawati, M. N., \& Gurusinga, R. (2017). The Effect of Effleurage and Abdominal Lifting Massage in the Labor Pain, 1-3. https://doi.org/10.5455/medscience.2017.06. 8670

Wulandari, P., \& Dwi, Prasita, N. H. (2015). Pengaruh Massage Effleurage Terhadap Pengurangan Tingkat Nyeripersalinan Kala I Fase Aktif Pada Primigravida Di Ruang Bougenville RSUD Tugurejo Semarang. Jurnal Keperataran Maternitas, 3(1), 59-67. 